\title{
Sistema português de saúde mental: avaliação crítica do modelo de pagamento aos prestadores
}

\author{
Julian Perelman ${ }^{\mathrm{a}, \mathrm{b}}$ Pedro Chaves ${ }^{\mathrm{a}}$ Joaquim Gago ${ }^{c}$ António Leuschner ${ }^{\mathrm{d}}$ \\ Alexandre Lourenço ${ }^{\text {e }}$ Ricardo Mestre ${ }^{f}$ Luis Pisco $^{g}$ Isabel Paixão ${ }^{h}$ \\ Álvaro de Carvalho ${ }^{i}$ José Caldas de Almeida ${ }^{j}$
}

${ }^{a}$ Escola Nacional de Saúde Pública - Universidade NOVA de Lisboa, Lisbon, Portugal; ${ }^{b}$ Centro de Investigação em Saúde Pública, Lisbon, Portugal; ' Centro Hospitalar de Lisboa Ocidental, Lisbon, Portugal; ${ }^{\mathrm{d}}$ Hospital de Magalhães Lemos, Porto, Portugal; ${ }^{e}$ Centro Hospitalar e Universitário de Coimbra, Coimbra, Portugal; ${ }^{f}$ Administração Central do Sistema de Saúde, Lisbon, Portugal; ${ }^{9}$ Administração Regional de Saúde de Lisboa e Vale do Tejo, Lisbon, Portugal; ' Administração Central do Sistema de Saúde, Lisbon, Portugal; 'Direção-Geral da Saúde, Lisbon, Portugal; jNOVA Medical School - Universidade Nova de Lisboa, Lisbon, Portugal

\section{Palavras chave \\ Saúde mental · Modelos de pagamento · Incentivos · Cuidados de saúde primários · Cuidados de saúde hospitalares}

\section{Resumo}

O Plano Nacional de Saúde Mental 2007-2016 aponta várias limitações ao sistema português de saúde mental, como a falta de acesso, os cuidados excessivamente centrados nos hospitais, a falta de recursos e a prevenção insuficiente. Uma das formas de atacar estes problemas é o desenho de um novo modelo de pagamento aos prestadores de cuidados de saúde mental, o que apenas é possível conhecendo em detalhe o modelo atual, os seus pontos fortes e fracos e os incentivos que cria. É isso que fazemos, com especial enfoque nos cuidados de saúde primários e hospitalares, com base nos resultados da literatura teórica e empírica, e na realização de um grupo focal com peritos das áreas da saúde mental e financiamento em Portugal. Concluímos que os cuidados de saúde primários não são incentivados a envolver-se na prevenção e tratamento de perturbações mentais, por beneficiarem da realização de um grande número de con-

\section{KARGER}

E-Mail karger@karger.com www.karger.com/pjp
(C) 2018 The Author(s) Published by S. Karger AG, Basel on behalf of NOVA National School of Public Health Karcer

Open access

This article is licensed under the Creative Commons AttributionNonCommercial-NoDerivatives 4.0 International License (CC BYNC-ND) (http://www.karger.com/Services/OpenAccessLicense) Usage and distribution for commercial purposes as well as any distribution of modified material requires written permission. sultas de curta duração e do cumprimento de objetivos que negligenciam a saúde mental. Já o pagamento dos hospitais Entidade Pública Empresarial é muito focado no nível de atividade e não na integração de cuidados. É prevista uma remuneração por dias ou episódio de internamento, ou por serviço médico prestado, o que dificulta uma visão global do estado de saúde de cada doente. No entanto, os indicadores definidos para estes prestadores e a ausência de um mecanismo de reembolso de custos privilegia a eficiência na prestação de cuidados. Os cuidados prestados na comunidade, cuja eficácia é defendida pela literatura, são incentivados por uma remuneração que Ihes é específica, mas que parece ainda não ter sido atribuída na prática. Em geral, apesar de ter alguns aspetos positivos, o modelo de pagamento aos prestadores de cuidados de saúde mental beneficiará de um novo desenho, que envolva mais os cuidados de saúde primários, que incentive uma visão global do estado de saúde de cada doente e que torne mais efetivo o tratamento na comunidade.

(c) 2018 The Author(s) Published by S. Karger AG, Basel on behalf of NOVA National School of Public Health

Álvaro de Carvalho passed away on the 4th of January 2018.
Julian Perelman

Escola Nacional de Saúde Pública Universidade NOVA de Lisboa PT-1600-560 Lisbon (Portugal) E-Mail JPerelman@ensp.unl.pt 
Portuguese Mental Health System: Critical Evaluation of the Providers' Payment Model

\section{Keywords}

Mental health · Payment models · Incentives .

Primary care $\cdot$ Secondary care

\section{Abstract}

The 2007-2016 National Plan of Mental Health points out several limitations of the mental health Portuguese system, such as bad access, a healthcare excessively concentrated on hospitals, lack of resources, and insufficient prevention. One way of dealing with such problems is to design a new model of payment to mental healthcare providers, which is only possible if we know the current model, its strengths and weaknesses, and the incentives it creates. That is what we do in this paper, with a special focus on primary and secondary care, on the basis of the theoretical and empirical literature, and the realization of a focus group with national mental health and financing experts. We conclude that primary care services have few incentives to be involved in the prevention and treatment of mental health disorders, as they benefit from conducting a large number of short-duration consultations and from reaching goals not related to mental health. The payment of "Entidade Pública Empresarial" hospitals is highly focused on the activity level and less on care integration. It includes a fee that depends on the number of days or episodes of inpatient stays, or on the number of medical acts, which makes it difficult for hospitals to have a global view of the patients' health status. However, the indicators defined for these providers and the inexistence of a cost reimbursement mechanism favor efficiency in healthcare provision. Community healthcare, which the literature defends to be effective, is incentivized by a specific fee, which, however, does not seem to be used in practice. In general, although having some interesting features, the current payment model for mental healthcare providers will benefit from a redesign which leads providers to have a global view of the patients' health status and to make an effective use of community care.

๑) 2018 The Author(s) Published by S. Karger AG, Basel on behalf of NOVA National School of Public Health

\section{Introdução}

O sistema de saúde mental português foi escrutinado em detalhe no Plano Nacional de Saúde Mental 20072016, publicado em 2008 [1]. O Plano documenta as várias limitações que o sistema apresenta. Destas, destacamos as duas para as quais existe mais evidência, e que são mais relevantes para o nosso propósito:

- Acesso limitado aos cuidados de saúde mental. O Estudo Epidemiológico Nacional realçou que apenas $15 \%$ dos doentes da amostra tinham recebido tratamento nos 12 meses anteriores [2]. Os dados do Inquérito Nacional de Saúde, realizado em 2014, demonstra que $48 \%$ das pessoas no primeiro quintil de rendimento tiveram acesso a cuidados de saúde mental [3].

- Excesso de internamentos, episódios de urgência e readmissões, versus intervenções na comunidade insuficientes. Os internamentos e consultas de urgência representam mais de $80 \%$ das despesas em saúde mental do SNS. Uma comparação internacional demonstrou que Portugal tinha lacunas importantes, em comparação com outros países europeus, em termos do desenvolvimento de equipas e centros de saúde mental comunitários [1].

Estes problemas são particularmente preocupantes num contexto de carga global de perturbações de saúde mental significativa e cada vez maior. Em Portugal, as perturbações de saúde mental contribuem para 11,7\% dos anos de vida ajustados pela incapacidade (DALYs) totais, o que quer dizer que são a segunda maior causa de DALYs a seguir às doenças cerebrovasculares [4]. Apesar de a taxa de suicídio causado por perturbações de saúde mental ter estado, em Portugal, claramente abaixo da média da OCDE em 2013 (8,7 por 100.000 habitantes versus 11,7 por 100.000 habitantes) [5], outros indicadores relacionados com saúde mental foram muito menos favoráveis. De acordo com o único estudo epidemiológico de saúde mental, realizado em 2008, Portugal era o que tinha a mais alta prevalência de qualquer uma das quatro principais perturbações de saúde mental (depressão, ansiedade, perturbações do impulso e abusos de substâncias), 22,9\%, comparado com um conjunto de nove países europeus.

A Organização Mental de Saúde (OMS) emitiu uma série de recomendações que parecem ir ao encontro dos problemas que o sistema português de saúde mental revela [1]. As principais recomendações são as seguintes:

- Organização da saúde mental em áreas geodemográficas, de forma a garantir o acesso ao tratamento de problemas de saúde; 
Table 1. Mecanismos de pagamento aos prestadores de cuidados de saúde (fonte: Charlesworth et al. [6])

\begin{tabular}{llllll}
\hline Integrado & & & & Não integrado \\
\hline $\begin{array}{l}\text { Orçamento } \\
\text { global }\end{array}$ & Capitação & Por caso & Por episódio & Per diem & Ao ato \\
\hline $\begin{array}{l}\text { Pagamento global } \\
\text { fixo periódico, } \\
\begin{array}{l}\text { independente do } \\
\text { número de } \\
\text { pacientes }\end{array}\end{array}$ & $\begin{array}{l}\text { Pagamento fixo } \\
\text { periódico por } \\
\text { utente registado } \\
\text { numa lista, para um } \\
\text { grupo de serviços }\end{array}$ & $\begin{array}{l}\text { Pagamento fixo } \\
\text { periódico por } \\
\text { paciente com um } \\
\text { diagnóstico } \\
\text { específico }\end{array}$ & $\begin{array}{l}\text { Pagamento por episódio } \\
\text { baseado em grupos de } \\
\text { doentes com diagnósticos, } \\
\text { procedimentos ou } \\
\text { necessidades similares }\end{array}$ & $\begin{array}{l}\text { Pagamento } \\
\text { por dia de } \\
\text { internamento }\end{array}$ & $\begin{array}{l}\text { Pagamento por } \\
\text { cada serviço e } \\
\text { contacto com o } \\
\text { paciente }\end{array}$ \\
\hline
\end{tabular}

- Integração de unidades e programas, incluindo unidades de internamento;

- Uma coordenação global da saúde mental;

- Envolvimento dos doentes, das suas famílias e das diferentes entidades comunitárias no tratamento;

- Articulação efetiva com os cuidados de saúde primários;

- Colaboração com o sector social e com organizações não-governamentais (ONGs) na reabilitação e cuidados de longa duração de doentes com perturbações mentais graves.

Existe assim uma grande diferença entre a adoção de boas práticas na prestação de cuidados de saúde mental a nível internacional e a realidade do sistema português de saúde mental. A melhoria deste sistema requer, entre outras, uma estratégia global, que inclua mudanças culturais, reformas organizacionais e diretrizes inovadoras. No entanto, estas mudanças complexas não serão implementadas se não forem adequadamente incentivadas, como demonstra a não implementação, em Portugal, das reformas neste sentido apontadas ao longo dos anos nos vários planos de saúde mental. O nosso artigo foca-se neste aspeto, os incentivos, na medida em que examinamos de que forma é que o modelo de pagamento atual em Portugal ajuda a explicar as limitações do sistema de saúde mental, e como é que mudanças nas modalidades de pagamento podem contribuir para que os prestadores portugueses executem as práticas recomendadas pela OMS.

\section{Modalidades de pagamento e incentivos: teoria e resultados}

Existem vários mecanismos que as entidades financiadoras da saúde podem utilizar para pagar aos prestadores de cuidados de saúde, de forma a incentivar certos tipos de comportamento. Com base em "Reforming Payment for Healthcare in Europe to Achieve Better Value" [6], ordenamos as modalidades de pagamento mais importantes de acordo com o grau de especificidade das medidas de atividade de que dependem, de forma crescente, e discutimos os incentivos que se espera que criem para os prestadores (ver Tabela 1). Mas, antes disso, explicamos o modelo de comportamento dos prestadores de cuidados de saúde de que nos socorremos para discutir o impacto que as várias modalidades de pagamento podem ter.

\section{Objetivos dos prestadores de cuidados de saúde}

Cada modalidade de pagamento gera incentivos que influenciam as práticas adotadas pelos prestadores. A influência das modalidades de pagamento nas práticas utilizadas não é simples de analisar de uma perspetiva teórica, na medida em que depende dos objetivos dos prestadores. No que diz respeito a prestadores individuais, é normalmente assumido que maximizam o seu rendimento, mas garantindo um benefício mínimo para os seus doentes que garanta a existência de procura [7]. Há ainda outros modelos que consideram que os prestadores têm preocupações éticas, o desejo de tratar casos interessantes, ou procuram atingir um certo nível de rendimento [7]. No que diz respeito aos hospitais, o modelo clássico que explica os objetivos por que se regem assume que têm o objetivo de maximizar o benefício dos doentes, mas garantindo a sua solvência (hospitais sem fins lucrativos), ou de maximizar o seu lucro, mas garantindo um mínimo de qualidade nos cuidados prestados de forma a terem procura para os seus serviços (hospitais com fins lucrativos) [8].

Neste estudo, optamos por seguir um modelo muito simples. Apesar de reconhecermos que os prestadores de cuidados de saúde mental podem ter várias preocupações 
que orientam a maneira como a sua atividade profissional é desenvolvida, focamo-nos em duas que nos parecem ser comuns a todos e as mais importantes: o seu rendimento e o estado de saúde dos doentes. Em algumas situações onde outros objetivos são claramente importantes, referimo-los, mas estes dois são os que guiam a nossa análise. Como este estudo diz respeito a modalidades de pagamento que influenciam de forma muito direta o rendimento dos prestadores, é a este objetivo que damos maior destaque.

\section{Orçamento global (OG)}

Este mecanismo de pagamento é fixo. Implica o pagamento de uma certa quantia ao prestador, que a usa para financiar a sua atividade durante o período a que o mecanismo se refere, normalmente um ano. Como o pagamento num mecanismo fixo não varia com a atividade do prestador, este mecanismo é incapaz de orientar o comportamento do prestador para objetivos muito específicos. Contudo, a dimensão do pagamento que pressupõe pode variar, o que lhe permite exercer alguma influência sobre o nível de esforço despendido pelo prestador no exercício da sua atividade, apesar de isto depender da motivação intrínseca e sentido de dever de cada profissional afetado. Este mecanismo é fácil de desenhar e implementar e, na medida em que não depende da divulgação de atividade, não incentiva a manipulação e falseamento de relatórios e dispensa a verificação e controlo do comportamento do prestador. Por outro lado, cria incentivos para a contenção de custos na prestação de cuidados de saúde, já que os custos de todos os serviços oferecidos são suportados pelo prestador [9]. Isto pode gerar eficiência, ou não, dependendo da capacidade e motivação do prestador para oferecer serviços de qualidade ao custo mais baixo possível. Por outro lado, o desejo de diminuir despesas pode levar a uma seleção de doentes, dificultandose o acesso àqueles cujos tratamentos são mais dispendiosos, ou a uma oferta de serviços de baixa qualidade. É ainda importante fazer referência aos salários fixos pagos aos profissionais de saúde, que são uma forma de orçamento global que lhes é atribuído. Este instrumento de financiamento tem a vantagem de não impor qualquer risco a estes profissionais, em oposição a outros instrumentos que dependem do nível de atividade, mas não tem a capacidade de criar incentivos para um bom desempenho $[10,11]$.

\section{Capitação (CAP)}

O pagamento previsto por este mecanismo depende do número de pessoas inscritas numa lista associada ao prestador. Esta lista contém todos os residentes numa certa área geográfica, quer tenham algum problema de saúde ou não.

A capitação pode induzir a prestação de serviços médicos de elevada qualidade, se os prestadores competirem entre si por inscrições nas suas listas, caso em que procuram manter os elementos que se encontram nas suas listas e atrair outros [10]. Espera-se que este mecanismo incentive a eficiência na prestação de serviços, já que o prestador tem interesse em controlar os custos que ele próprio suporta, mantendo a qualidade da sua atividade. Caso as listas sejam fixas e não haja competição por inscrições, a eficiência pode dar lugar à contenção de custos, se o prestador não tiver motivação interna ou capacidade para manter padrões de elevada qualidade a baixo custo. $\mathrm{O}$ facto de o prestador ser pago de acordo com o número de elementos da sua lista e não de acordo com aqueles que são efetivamente tratados incentiva o prestador a evitar os doentes cujo tratamento implique um custo mais elevado, recusando a entrada na sua lista ou, no caso dos médicos de cuidados de saúde primários, referenciando-os para os cuidados hospitalares, o que é ineficiente nos casos em que o tratamento é possível e desejável nos cuidados de saúde primários [11].

\section{Pagamento por caso (PPC)}

O valor a pagar através deste mecanismo de pagamento depende do número de pessoas que sofrem de uma perturbação específica [12] e estão inscritas numa lista associada a um prestador. A única diferença que este mecanismo exibe em relação à capitação é o facto de as listas que prevê conterem pessoas com um certo problema de saúde e não as residentes numa certa área geográfica. Desta forma, cria basicamente os mesmos incentivos que a capitação, que foram já descritos. No entanto, o facto de estar associado a uma doença específica pode ainda levar a um diagnóstico exagerado dessa mesma doença e a altas tardias para adiar a saída de elementos da lista associada a um prestador.

\section{Pagamento por episódio (PPE)}

Este mecanismo prevê um pagamento que depende do número de episódios tratados pelos prestadores. Um episódio corresponde a um tipo de contacto com os serviços de saúde (o mais habitual é um episódio de internamento). Um sistema de classificação de problemas de saúde (os sistemas GDH são os mais conhecidos) identifica o conjunto de possíveis diagnósticos e é associado um valor fixo a cada um, para cada episódio.

A ausência de qualquer relação entre o nível de custos dos prestadores e o valor previsto por este mecanismo in- 
centiva a procura pela eficiência, já que a diferença entre o pagamento recebido pelos prestadores pelo tratamento de um doente e aquilo que lhes custa fazê-lo é inteiramente da sua responsabilidade [12]. Contudo, a contenção de custos não é necessariamente uma realidade, já que o nível de atividade pode ser excessivo, ainda que cada serviço médico seja prestado de forma eficiente. Para além disso, o desejo dos prestadores de produzir uma grande quantidade de episódios a um custo baixo pode prejudicar a qualidade dos serviços prestados [9]. Finalmente, pode gerar um número excessivo de episódios e incentivar uma classificação enviesada do tipo de episódios e a seleção de doentes com episódios mais rentáveis [9].

\section{Pagamento per diem (PPD)}

Este mecanismo paga aos prestadores de acordo com a duração dos internamentos dos seus doentes. Por cada dia que os doentes passam nas instalações do prestador, este recebe um valor fixo. É um mecanismo muito objetivo e fácil de aplicar, mas o facto de financiar os internamentos de acordo com a sua duração pode levar a que esta se prolongue mais do que seria ideal. $\mathrm{Na}$ verdade, os doentes podem ser internados por mais tempo do que é necessário e ser sujeitos a tratamentos excessivamente longos e não necessariamente eficazes.

\section{Fee-for-service (FFS)}

No caso deste mecanismo, é o número de atos médicos de cada tipo que são prestados que define o valor a pagar ao prestador. O pagamento a atribuir a cada ato médico é definido antes de ele se realizar e toda a atividade é paga depois de ocorrer. É um mecanismo que recompensa os médicos que seguem o estado de saúde dos seus doentes, prestando-lhes todos os cuidados de que necessitam, assim como aqueles que seguem doentes cujo tratamento tem um custo mais elevado, porque os serviços médicos necessários para tratar este tipo de doentes são normalmente os que são alvo de um pagamento mais generoso [11]. Isto implica que a acessibilidade não deve ser um problema quando este mecanismo é aplicado. Mas há também efeitos perversos a referir. Por um lado, atos médicos desnecessários mas bem pagos podem ser privilegiados em detrimento de outros mais úteis [7, 11]. Por outro, a classificação dos atos médicos prestados pode ser manipulada em favor daqueles que implicam pagamentos mais altos. E ainda se pode verificar, nos cuidados de saúde primários, uma sub-referenciação, já que os médicos pagos através deste mecanismo poderão querer tratar doentes que seriam mais eficiente ou eficazmente seguidos pelos cuidados hospitalares [11].

Sistema português de saúde mental

\section{Pay-for-performance (P4P)}

Finalmente, este mecanismo pressupõe um pagamento que depende do número de objetivos atingidos, de entre aqueles que estão definidos à partida. Atribui recompensas aos prestadores que obtêm resultados específicos, ou penaliza aqueles que não o conseguem. É um mecanismo que se foca nos processos utilizados, ou nas consequências verificáveis que deles decorrem.

A aplicação deste mecanismo é uma forma muito eficaz de alinhamento dos incentivos do prestador com as necessidades da população, já que o cumprimento de certas metas pré-definidas não beneficia apenas o estado de saúde da população, mas também o prestador, que é recompensado por atingi-las. Apesar disso, é importante não tornar o pagamento ao prestador muito dependente deste mecanismo, na medida em que o resultado da atividade do prestador é influenciado pelo comportamento dos seus doentes e por outros fatores que não consegue controlar. Este mecanismo pode, desta forma, ser por vezes injusto, nomeadamente quando pune prestadores que prestam serviços médicos de qualidade, ou quando recompensa aqueles que cumprem o seu papel de forma pouco cuidada, o que ocorre quando fatores fora do controlo dos prestadores impedem que o esforço que exercem e a qualidade dos processos que utilizam se alinhem com os resultados obtidos [13]. Existe também o perigo de os prestadores se focarem excessivamente nos objetivos cuja prossecução implica uma remuneração, negligenciando os restantes. Este mecanismo pode ainda ter consequências negativas já mencionadas na análise dos restantes, como a manipulação da informação como forma de obter recompensas [9] e a seleção de doentes, privilegiando aqueles cujo tratamento contribui para o cumprimento de objetivos remunerados e evitando os restantes.

\section{Modalidades de pagamento: evidência empírica para a saúde mental}

Poucos modelos de pagamento alternativos têm sido testados em SM, e aqueles que foram experimentados têm apresentado resultados ambíguos, principalmente nos EUA. Em 1995, Dwyer e colaboradores [14] avaliaram o impacto da mudança de modelo de pagamento de FFS para capitação dos cinco centros comunitários de saúde mental existentes na cidade de Rochester, Estado de Nova Iorque. Neste novo modelo (doravante, o "primeiro modelo"), os centros foram pagos através de um mecanismo de capitação pré-pago, o qual é baseado na utilização prévia por parte dos doentes dos serviços hospitalares. Nesta experiência, os centros ficaram responsáveis pelos custos 
dos serviços prestados na comunidade e pelos custos hospitalares dos doentes que seguem. De acordo com os autores, o novo mecanismo de pagamento aos prestadores permitiu uma poupança de custo de pelo menos $20 \%$ (no melhor cenário $75 \%$ ) por ano sem alterações significativas do bem-estar psicológico dos doentes. Esta poupança de custos deveu-se, essencialmente, à diminuição do número de dias de internamento.

Entre agosto e setembro de 1995, foi implementado no Estado do Colorado o programa piloto "Colorado Medicaid Capitation". Este programa alterou o método de pagamento dos serviços prestados a doentes com doença mental grave através do Medicaid de FFS para capitação. Neste novo modelo (doravante o "segundo modelo"), a capitação teve um valor fixo por doente elegível para tratamento. $\mathrm{O}$ valor da capitação cobria todos os cuidados hospitalares (internamento, consultas), cuidados de enfermagem ao domicílio e cuidados nos hospitais estatais para pessoas com idade inferior a 21 anos e acima dos 65 anos. A medicação continuava a ser paga através do FFS.

Em 2002, e com dados de 1995 a 1998, Bloom e colaboradores [15] concluíram que o custo por pessoa diminuiu quando comparado com o FFS nos dois anos seguintes após a implementação. Adicionalmente, os autores concluíram que houve uma redução do acesso aos cuidados em ambos os modelos de capitação. No entanto, apenas no segundo modelo é que se verificou uma redução da utilização por parte dos doentes com perturbações mentais. Os autores apontam como possível explicação o facto de neste segundo modelo só se ter investido no desenvolvimento de novos serviços após poupanças conseguidas no primeiro ano de implementação. Já no primeiro modelo, os investimentos em novos serviços foram feitos antes da implementação do modelo de capitação. Uma atualização deste estudo foi feita em 2011, considerando 5 anos de seguimento. Neste estudo os autores concluíram que para ambos os modelos houve uma redução significativa dos custos dos tratamentos mais caros (internamento). No entanto, apenas no segundo modelo é que se verificou uma redução significativa do custo por utilizador em todos os serviços.

Em 2005, Chou e colaboradores [16] analisaram o impacto da alteração do financiamento no Estado do Colorado ao nível dos cuidados de saúde prestados em ambulatório. Para isso, o estudo comparou os dois modelos de capitação implementados no Estado do Colorado, e mencionados anteriormente, com o modelo que estava em vigor, o FFS. Os autores concluíram que os prestadores pagos através dos sistemas de capitação apresentaram níveis de utilização iniciais mais elevados em todos os serviços prestados em ambulatório quando comparado com os prestadores pagos através do FFS. Adicionalmente, os autores concluíram que houve uma maior integração dos serviços e, no período pós-capitação, a prestação de serviços mais complexos decresceu.

De forma geral, relativamente ao financiamento através dos Grupos de Diagnóstico Homogéneos (GDHs) ${ }^{1}$, alguns estudos mostram que este mecanismo de reembolso aplicado à saúde mental tende a subfinanciar os serviços de saúde mental. A razão apontada por Knapp e colaboradores [17] é que as taxas de reembolso nem sempre abrangem todos os custos associados às doenças mentais crónicas. A literatura sugere que o reembolso dos custos de saúde mental baseado num sistema de casemix deve considerar não só o tempo de internamento, mas também o diagnóstico, o grau de apoio social e de assistência nas atividades do dia-a-dia, a severidade da doença, se houve ou não referenciação pelo sistema judicial e a possibilidade de existir um comportamento "perigoso" [18]. Desta forma, Knapp e colaboradores [17] argumentam que nos países onde existam dados suficientes sobre a utilização dos recursos e custos, os GDHs, se bem construídos, podem apresentar-se como um modelo que assegura que recursos suficientes são transferidos para os cuidados secundários e especializados de saúde mental. Neste contexto, definir um ajustamento ao risco adequado torna-se crucial, de forma a evitar problemas de financiamento.

Em termos da saúde mental, Zechmeister e colaboradores [19] mostram que, na Áustria, o sistema baseado em GDHs iniciado em 1997 conduziu à desinstitucionalização, ou seja, ao fecho de hospitais psiquiátricos e abertura de departamentos de psiquiatria em hospitais gerais. No entanto, e devido à falta de informação sobre a complexidade dos tratamentos e procedimentos usados, este sistema subestimou os custos dos tratamentos das perturbações mentais, levando a que os hospitais enfrentassem défices elevados [17]. Como consequência, foram criados incentivos para internamentos mais curtos do que seria desejável e para exclusões indevidas de doentes [11]. Em 2009, um novo sistema de categorização dos procedimentos foi implementado. Houve um ajustamento dos grupos de diagnóstico, nomeadamente ao nível dos tempos de internamento, e atualizaram-se os pontos associados a cada grupo. Assim, cada ponto equivale a um euro. Esta reforma, aliada a planos estruturais e gestão de qualidade, permitiu a criação de um sistema mais eficaz, com maiores benefícios para os doentes, tempos de internamento

\footnotetext{
Este sistema de reembolso de custos tem em conta a diversidade e complexidade do tratamento dos doentes, através do cálculo do índice casemix.
}

Perelman et al. 
mais baixos e taxas de crescimento anuais dos custos hospitalares mais reduzidas [20]. Em termos de saúde mental, estando esta reforma aliada ao ajustamento dos tempos de internamento de forma a considerar os diferentes níveis de necessidade clínica, bem como a complexidade do seu tratamento, permitiu promover um sistema mais orientado para a comunidade e em que os hospitais psiquiátricos são capazes de cobrir os seus custos [17].

No Reino Unido, o pagamento por resultados é o método usado como pagamento aos hospitais pertencentes ao Serviço Nacional de Saúde (NHS). Apesar do nome, este método não visa pagar aos prestadores por resultados obtidos. Ao invés, remunera a "atividade" usando os Healthcare Resources Groups (HRG). Os HRGs agregam os diagnósticos e intervenções que consomem níveis similares de recursos do NHS. A cada HRG está associado um preço, que é calculado com base na média nacional dos custos. A esta média são ainda feitos ajustamentos de forma a que o preço reflita as boas práticas clínicas e não apenas a média dos custos. Relativamente à saúde mental, numa fase inicial, este método baseava-se num conjunto de contratos realizados entre o Estado e os prestadores. No entanto, este método de financiamento oferecia poucos incentivos aos prestadores para darem resposta, de uma forma eficiente, às necessidades de cuidados de saúde mental [21]. Recentemente, e através de orientações políticas, introduziram-se os Mental Health Clusters, um financiamento baseado no caso. Os clusters agregam os doentes numa de 21 categorias, de acordo com as suas necessidades ${ }^{2}$. Os prestadores dos serviços são pagos por cada período de tratamento do doente, enquanto este é classificado em determinado cluster. A cada cluster/caso está associado um preço fixo. Para este método funcionar, os custos não podem variar significativamente dentro dos vários clusters nem entre prestadores. De forma a evitar que tal aconteça, os doentes são agrupados de forma homogénea, tendo em conta as suas necessidades e níveis de utilização dos recursos [22]. Uma vez que descreve as necessidades dos doentes com perturbações mentais, este modelo é mais abrangente do que o método baseado no puro diagnóstico [1].

O pagamento por caso foi analisado por Jacobs e colaboradores [21] com o objetivo de verificar se há homogeneidade dentro dos clusters em termos de custos, níveis de atividade/recursos utilizados e se os doentes que são agrupados num determinado cluster têm níveis similares de necessidade. Os resultados mostram uma variação

\footnotetext{
2 Em cada cluster está estipulado o intervalo de tempo para que o médico faça a reavaliação do doente em termos de codificação.
}

Sistema português de saúde mental substancial entre prestadores em termos de custos, tratamentos prestados e tempos de internamento dentro do mesmo cluster. A existência destas assimetrias dentro dos clusters torna difícil determinar corretamente um nível mínimo de serviços prestados para cada cluster. Os autores sugerem que, apesar de se verificar heterogeneidade nos custos, tratamentos e necessidades, este método de pagamento não deve ser abandonado, mas sim redesenhado com o objetivo de obter clusters homogéneos.

Em conclusão, existem poucos estudos empíricos sobre o impacto de modelos de pagamentos alternativos aos prestadores de cuidados de saúde mental. A maioria dos estudos são provenientes dos EUA, e mostram os benefícios do pagamento por capitação em relação ao pagamento ao ato. Com base nos estudos europeus, podemos concluir que os GDHs per se não são um mecanismo eficiente de financiamento, uma vez que subestimam os custos da saúde mental, sendo necessária a construção de sistemas de classificação específicos para a saúde mental, que deverão garantir não só a homogeneidade dentro de cada grupo de diagnóstico, mas também a homogeneidade entre prestadores de cuidados dentro do mesmo grupo de diagnóstico.

\section{Critérios de avaliação das práticas em saúde mental}

Para ser possível a avaliação dos incentivos criados pelas diferentes modalidades de pagamento aos prestadores de cuidados de saúde mental em Portugal, escolhemos sete critérios que detalhamos a seguir. Este conjunto de critérios foi inspirado por World Health Organization [23], The REFINEMENT Project [9] e Wilson e colaboradores [24].

\section{Abrangência dos cuidados de saúde primários,}

\section{incluindo a saúde mental}

É desejável, do ponto de vista da eficiência, que os cuidados de saúde primários se envolvam na saúde mental, tratando as perturbações mais leves, de forma a que os prestadores mais especializados possam concentrar a sua atenção nas mais graves. Para que isto aconteça, os médicos de família devem ter a capacidade de avaliar os sintomas e as condições de vida dos doentes, estabelecer diagnósticos e prescrever diferentes tratamentos. Para além da eficiência que isto pode gerar e dos benefícios que cria para os doentes, a oferta de um conjunto de serviços abrangente reforça o papel dos cuidados de saúde primários, o que é benéfico para os sistemas de saúde [24]. 


\section{Continuidade dos cuidados}

Este critério refere-se à relação de longo prazo entre o doente e o seu médico, incluindo também o que se passa entre diferentes episódios de doença. A continuidade do tratamento é favorecida pela qualidade dos serviços prestados e pela comunicação com e respeito pelo doente [24]. Tem sido demonstrado que a continuidade do tratamento, na saúde mental, está associada a boa qualidade de vida e sintomas menos graves [25].

\section{Coordenação dos cuidados}

Aqui, referimo-nos à definição de diferentes formas de cooperação entre os cuidados de saúde primários e os cuidados especializados de saúde mental, incluindo padrões de referenciação, contactos regulares, partilha de responsabilidades nas decisões e integração de serviços. A coordenação assume uma importância especial na saúde mental, dada a vasta gama de recursos (médicos, sociais e psicológicos) a que recorre e a diversidade de atores que nela estão envolvidos [26]. Do ponto de vista da eficiência, a coordenação reduz custos desnecessários, a duplicação de serviços e o risco de erros clínicos [24]. Há também evidência que a coordenação dos cuidados (com os cuidados de saúde primários a assumirem um papel importante) permite a prestação de cuidados integrados, o que se sabe ser uma forma custo-efetiva de tratar doentes com perturbações mentais graves [27].

\section{Prevenção de perturbações}

Está cada vez mais claro que existem várias intervenções que podem prevenir o surgimento de perturbações de saúde mental, ou diminuir a sua gravidade quando surgem, intervenções essas que são custo-efetivas (para uma revisão sobre o tema, consultar Knapp e colaboradores [28]). O facto de incluirmos a prevenção como um critério significa que acreditamos que os prestadores devem ser incentivados a realizar atividades neste âmbito, tais como intervenções precoces direcionadas para psicoses, programas escolares e parentais que previnam distúrbios comportamentais e medidas de segurança e prevenção do suicídio.

\section{Acessibilidade dos cuidados}

A acessibilidade refere-se à possibilidade dada a todos os cidadãos de recorrerem a cuidados de saúde quando necessário, independentemente das suas caraterísticas pessoais, como estado de saúde ou estatuto socioeconómico. $\mathrm{O}$ acesso aos cuidados de saúde pode ser restringido através de barreiras financeiras (copagamentos), da distância geográfica ou de tempos de espera, por exem- plo. Quanto melhor for a acessibilidade, mais fácil é a satisfação de necessidades dos doentes e a prestação de cuidados de saúde de longa duração [26].

\section{Não-discriminação nos cuidados}

A não-discriminação refere-se ao tratamento de todos os doentes com os mesmos padrões de qualidade, respeitando a equidade horizontal (o mesmo tratamento para as mesmas necessidades) e a equidade vertical (melhor tratamento para necessidades mais prementes). É um objetivo comum a todos os sistemas de saúde, mas é de particular importância na saúde mental, dados os problemas de acesso e a padronização social das perturbações mentais.

\section{Eficiência dos cuidados}

Verifica-se quando as práticas mais eficientes, ou seja, aquelas que produzem os melhores resultados utilizando a menor quantidade de recursos, são utilizadas. É importante notar, no entanto, que a estrutura de custos dos departamentos de saúde mental difere fortemente da estrutura de custos de outros departamentos hospitalares, por ser determinada principalmente pelos recursos humanos, sendo que as tecnologias (medicação, teste, exames, etc.) têm um peso pouco elevado. Por isso, a eficiência está mais relacionada na forma como os profissionais são alocados a diferentes tarefas, tornando-os potencialmente mais produtivos, do que numa utilização mais criteriosa das tecnologias, como poderá ser o caso noutros departamentos hospitalares.

\section{Mapeamento de prestadores de cuidados de saúde mental em Portugal}

A Figura 1 contém um mapeamento dos prestadores de cuidados de saúde mental em Portugal, distinguindo os cuidados de saúde primários dos especializados. Este mapeamento foi inspirado em Joint Action on Mental Health and Well-Being [29].

Há três tipos de unidades funcionais de cuidados de saúde primários, que devem ser o primeiro passo na ligação entre a população e o Serviço Nacional de Saúde (SNS), procedendo ao tratamento de alguns doentes e referenciando outros: as Unidades de Cuidados de Saúde Personalizados (UCSP), as Unidades de Saúde Familiar do Tipo A (USF-A) e as Unidades de Saúde Familiar do Tipo B (USF-B). Para além disso, há ainda três tipos de unidades funcionais, que prestam suporte às diferentes unidades apresentadas acima: as Unidades de Cuidados na Comunidade (UCC), as Unidades de Recursos Assistenciais Partilhados (URAP), e as Unidades de Saúde Pú- 


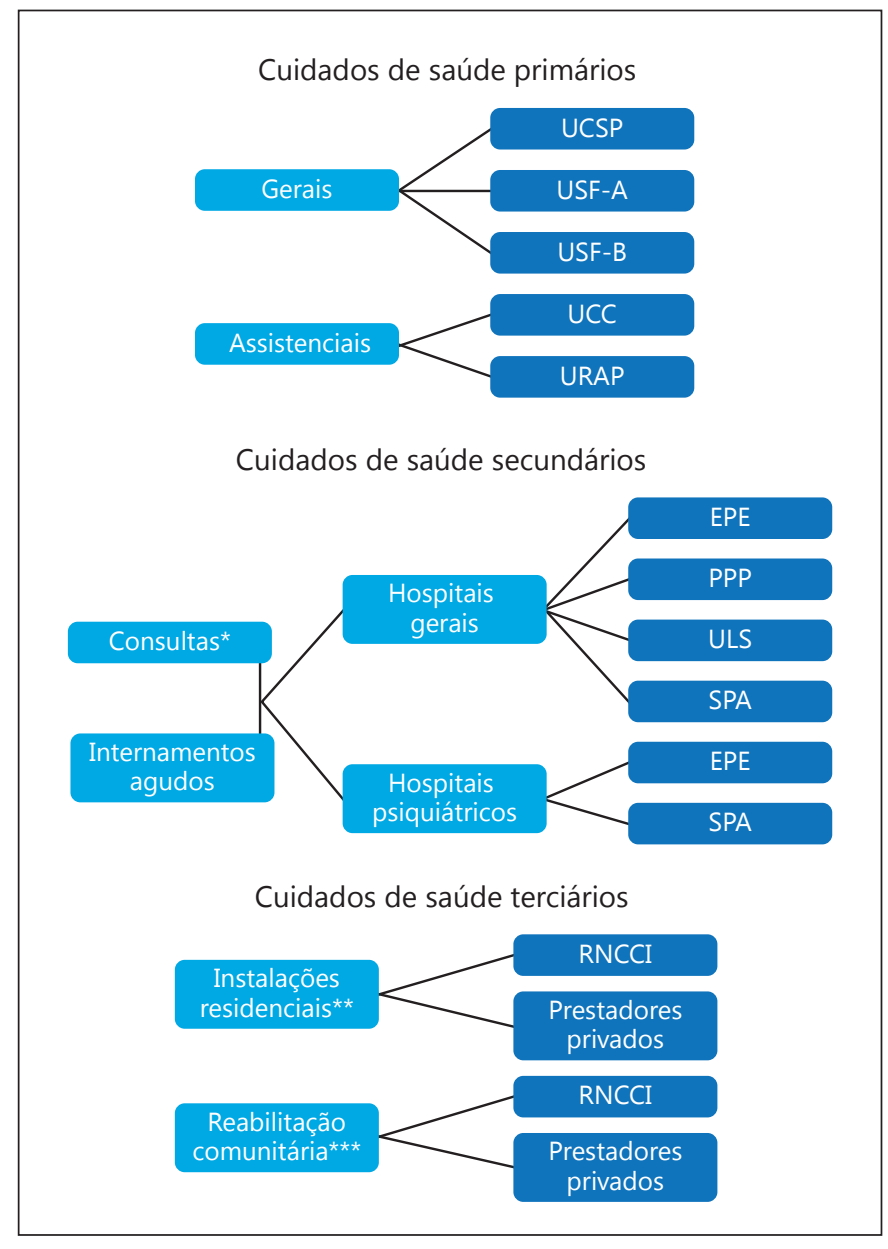

Fig. 1. Serviços e prestadores de cuidados de saúde mental em Portugal. UCSP, Unidade de Cuidados de Saúde Personalizados; USF, Unidade de Saúde Familiar; UCC, Unidade de Cuidados na Comunidade; URAP, Unidades de Recursos Assistenciais Partilhados; EPE, Entidade Pública Empresarial; PPP, Parceria PúblicoPrivada; ULS, Unidade Local de Saúde; SPA, Setor Público-Privado; RNCCI, Rede Nacional de Cuidados Continuados Integrados. * Departamentos de consultas externas de saúde mental, centros comunitários de saúde mental e instalações de tratamento de dia. ** Unidades residenciais, unidades socio ocupacionais e equipas de visitas ao domicílio. ${ }^{* * *}$ Unidades comunitárias de reabilitação, unidades de reabilitação de alta dependência e unidades de cuidados de longa duração.

blica (USP), que não analisamos por não serem as entidades mais representativas dos cuidados de saúde primários, em termos de dimensão, orçamento e atividade (encontram-se descritas no relatório disponível online, em http://www.aasilva.com/mental-health/backend/wpcontent/uploads/2017/04/destaque.pdf).

Há três estatutos de hospitais em Portugal, cada um com o seu modelo de pagamento: o Hospital "Entidade
Pública Empresarial” (EPE), o Hospital "Parceria Público-Privada" (PPP), e o Hospital "Setor Público Administrativo" (SPA). Acrescenta-se que, ao nível organizacional, os hospitais gerais podem estar organizados sob a forma de Unidades Locais de Saúde (ULS), estruturas que abrangem cuidados hospitalares e cuidados de saúde primários. Embora haja departamentos de saúde mental nos três estatutos, os hospitais EPE representam 33 hospitais sobre um total de 45 hospitais públicos em Portugal, pelo que optamos por centrar a nossa análise nesta categoria.

Finalmente, os cuidados de saúde terciários são prestados por dois tipos de unidades, que se distinguem pela natureza dos serviços que prestam aos doentes. O primeiro grupo inclui instalações residenciais não hospitalares relacionadas ou não com saúde para doentes com perturbações mentais relativamente estáveis, nomeadamente unidades residenciais, unidades socio ocupacionais e equipas de suporte domiciliário. Já o segundo oferece essencialmente serviços comunitários de reabilitação, que incluem cuidados não intensivos, unidades direcionadas para doentes altamente dependentes e instalações de cuidados de longa duração.

\section{Metodologia}

Foi realizada uma avaliação crítica dos modelos de pagamento dos prestadores de cuidados de saúde mental em Portugal, focando os cuidados de saúde primários e secundários. Este modelo foi desenvolvido com base em dois métodos. Em primeiro lugar, foi realizada uma análise económica detalhada dos modelos de pagamento dos prestadores de forma geral e da prestação de cuidados de saúde mental no sistema de saúde português. Esta análise é essencialmente teórica, baseada nos incentivos identificados na literatura, apresentada acima, das diferentes formas de pagamento. Por exemplo, analisámos de forma crítica os incentivos criados pelo pagamento baseado no volume de serviços prestados ao nível hospitalar.

Em segundo lugar, foi organizado um grupo focal com peritos da área da saúde mental e da área do financiamento dos prestadores de cuidados de saúde. Este grupo focal foi realizado no dia 28 de setembro de 2015, e juntou 8 peritos:

- dois médicos psiquiatras, dos quais um diretor de serviço de saúde mental de um hospital geral;

- três administradores hospitalares de hospitais psiquiátricos e gerais;

- três representantes de instituições centrais e regionais do sistema de saúde.

O grupo focal tinha como principal tarefa avaliar o impacto das modalidades de pagamento dos cuidados de saúde primários e secundários, de acordo com cada um dos sete critérios apresentados acima. Para tal, foi apresentada a apreciação dos investigadores sobre este impacto, com base na literatura, sendo pedido aos participantes para confirmar ou não a sua existência no contexto português, com a possibilidade de apresentação de efeitos alternativos. 
Table 2. Mecanismos de pagamento das diferentes unidades gerais de cuidados de saúde primários

\begin{tabular}{llllll}
\hline Unidade & $\begin{array}{l}\text { Salário } \\
\text { fixo }\end{array}$ & $\begin{array}{l}\text { P4P } \\
\text { coletivo }\end{array}$ & $\begin{array}{l}\text { P4P } \\
\text { individual }\end{array}$ & Capitação & $\begin{array}{l}\text { Fee-for- } \\
\text { service }\end{array}$ \\
\hline UCSP & $\checkmark$ & & & \\
USF-A & $\checkmark$ & $\checkmark$ & & & \\
USF-B & $\checkmark$ & $\checkmark$ & $\checkmark$ & $\checkmark$ & $\checkmark$ \\
\hline
\end{tabular}

Table 3. Incentivos esperados dos mecanismos de pagamentos aos cuidados gerais de saúde primários

\begin{tabular}{llll}
\hline Critério & UCSP & USF-A & USF-B \\
\hline Abrangência & -- & -- & - \\
Continuidade & - & - & + \\
Coordenação & - & - & - \\
Prevenção & - & - & - \\
Acessibilidade & - & - & - \\
Não-discriminação & 0 & - & - \\
Eficiência & 0 & + & + \\
\hline
\end{tabular}

++, altamente provável; +, moderadamente provável; 0 , neutro; -, moderadamente improvável; --, altamente improvável.

\section{Cuidados de saúde primários}

Como já mencionámos, os cuidados de saúde primários em Portugal são prestados por diferentes tipos de unidades, que diferem na sua organização e na forma como são pagas. As UCSP enquadram-se no modelo tradicional de centros de saúde, que estava em vigor antes da reforma dos cuidados de saúde primários de 2006. Os profissionais das UCSP recebem um salário fixo, definido por lei e que depende do número de horas de trabalho semanais e do número de anos de experiência. Os profissionais das USF-A também recebem um salário fixo mas, para além disso, são avaliados com base numa série de indicadores de qualidade. É definida uma meta quantitativa para cada objetivo e atribuída uma pontuação global à USF-A, baseada no sucesso obtido pelos seus profissionais no alcance das metas. Desta forma, cria-se um incentivo financeiro coletivo, já que as eventuais recompensas são atribuídas à USF-A no seu todo e não aos seus profissionais individualmente, e apenas podem ser utilizadas em ações coletivas. Finalmente, os médicos de família das USF-B partilham com aqueles que trabalham nas USF-A as suas duas componentes de pagamento, o salário fixo e os prémios por desempenho coletivo. Podem também re- ceber prémios por desempenho individual, tais como os enfermeiros e administradores destas unidades. Para além disso, recebem um montante dependente da extensão da sua lista de doentes (o que corresponde a um mecanismo de pagamento de capitação geográfica). Tanto os prémios individuais como o montante pago através de capitação são complementos ao salário e podem ser despendidos livremente pelos profissionais. Há ainda a referir uma componente de FFS, já que os médicos recebem $30 €$ por cada consulta domiciliária que realizam, até um máximo de 20 por mês. A Tabela 2 resume as modalidades de pagamento dos diferentes tipos de unidades principais de cuidados de saúde primários.

Analisando a lista de indicadores utilizados para avaliar o desempenho das USF em 2015 [30], é possível indicar aqueles que dizem respeito à saúde mental:

- Um indicador nacional obrigatório para todas as USF: proporção de doentes, entre aqueles com 65 anos ou mais, sem prescrições de ansiolíticos, sedativos e hipnóticos;

- Três indicadores que podem ser escolhidos voluntariamente ao nível regional ou local: (i) proporção de doentes, entre aqueles com 18 anos ou mais, com diagnóstico de depressão com prescrição de terapia antidepressiva; (ii) proporção de doentes, entre aqueles com 14 anos ou mais, com registo de consumo de álcool nos três anos mais recentes; (iii) proporção de doentes, entre aqueles com 14 anos ou mais, com um problema de "consumo excessivo de álcool" que foram alvo de pelo menos uma consulta nos três anos mais recentes.

\section{Incentivos esperados}

A Tabela 3 resume a nossa visão sobre os incentivos produzidos por estas modalidades, na perspetiva da saúde mental. Os médicos de família não têm incentivos financeiros para se envolverem no tratamento de perturbações mentais. As modalidades de pagamento atualmente em vigor contribuem para isso de pelo menos três formas:

- Os médicos das USF-B são altamente incentivados, pelas modalidades de capitação e P4P, a tratar um grande número de doentes, o que poderá dar lugar à realização de um grande número de consultas. Como o diagnóstico e o tratamento de perturbações mentais consomem muito tempo, poderão ter tendência a ser negligenciadas pelos médicos de família. Nas USF-A, esta situação poderá ter menos importância porque o efeito do P4P é atenuado pelo facto de os incentivos serem pagos à equipa e não aos profissionais. Apesar de esta situação não ocorrer nas UCSP, o grande número 
de doentes que têm que tratar e o número insuficiente de médicos de família em algumas regiões [31] não são favoráveis à realização de consultas longas [32].

- Os indicadores relacionados com a saúde mental têm uma importância residual no mecanismo de $\mathrm{P} 4 \mathrm{P}$, havendo apenas um indicador apenas ao nível nacional, relacionado com a prescrição excessiva de ansiolíticos. $\mathrm{O}$ indicador referente ao diagnóstico e tratamento da depressão é utilizado apenas se as USF o decidirem, e ao nível regional ou local. Ainda assim, o facto de estes indicadores existirem leva-nos a concluir que o desincentivo para o envolvimento nos cuidados de saúde mental é menor nas USF do que nas UCSP.

- Nas UCSP, os médicos de família não são incentivados a funcionar verdadeiramente como gestores do acesso aos cuidados hospitalares, ainda que formalmente estejam incumbidos desta tarefa, já que não são penalizados por referenciação excessiva, nem recompensados por tratarem os doentes com os quais contactam. De facto, o salário fixo que constitui a base da sua remuneração incentiva a referenciação e não o tratamento. Como o salário fixo assume uma importância relativa superior nas UCSP, concluímos que é nestas unidades que os médicos de família estão menos motivados para tratar doentes com perturbações mentais.

A continuidade dos cuidados deverá ser um dos pontos fortes dos profissionais das USF, dada a componente de capitação do modelo de pagamento que se lhes aplica. Esta componente ajuda a explicar o significado da expressão "médico de família", já que esta figura é responsável pelo seguimento dos doentes da sua lista. No entanto, como já foi referido, o pagamento dos cuidados de saúde primários é totalmente independente do pagamento dos hospitais, pelo que a continuidade deve ser apenas entendida ao nível dos cuidados de saúde primários, e não ao nível do percurso do doente, que poderá passar por vários níveis de cuidados. Finalmente, como a capitação está ausente do modelo de pagamento que se aplica às UCSP, não é de esperar que haja continuidade nos cuidados de saúde oferecidos por estas unidades.

Os médicos de família não têm incentivos financeiros para se coordenarem ou colaborarem com outros prestadores por pelo menos duas razões:

- O pagamento aos médicos de família é totalmente independente daquele que se aplica aos cuidados de saúde especializados. Mais especificamente, o pagamento é fragmentado pelos diferentes prestadores e os orçamentos independentes que existem criam diferentes incentivos para cada prestador.

Sistema português de saúde mental
- O tratamento de perturbações mentais não se configura como uma prioridade na lista de indicadores do mecanismo de $\mathrm{P} 4 \mathrm{P}$, o que implica que os médicos de família não tenham qualquer incentivo para usar o seu tempo em reuniões com especialistas em saúde mental, de forma a melhorar o tratamento e o seguimento dos seus doentes com perturbações mentais. Contudo, o facto de a lista conter indicadores relacionados com a saúde mental, ainda que poucos, significa que alguma atenção deve ser prestada a este tipo de perturbações.

Não há grande diferença entre os incentivos que cada um dos tipos de unidades funcionais de cuidados de saúde primários tem para contribuir para a prevenção de perturbações mentais. De facto, todos os três tipos de unidades são responsáveis pelos custos da sua atividade o que, assumindo que o custo de implementação de uma política de prevenção efetiva é superado pelas poupanças em futuros tratamentos, deveria encorajar todos eles a afetar alguns dos seus recursos a esta área. Contudo, a escassez de recursos humanos nos cuidados de saúde primários portugueses leva a que as atividades não consideradas essenciais, como as relacionadas com prevenção, sejam normalmente negligenciadas. Para além disso, os indicadores ligados à saúde mental da lista do mecanismo de $\mathrm{P} 4 \mathrm{P}$ aplicado às USF não fazem qualquer menção à prevenção, levando a que os médicos de família direcionem a sua atenção para outras atividades com potencial de remuneração. Levando tudo isto em consideração, consideramos que o atual modelo de pagamento não favorece a prevenção de perturbações mentais.

Os modelos de pagamento dos três tipos de unidades geram os mesmos incentivos no que diz respeito à acessibilidade dos cuidados de saúde. As consequências negativas que adviriam da recusa em tratar um doente elegível por parte de uma unidade de cuidados de saúde primários, nomeadamente os danos reputacionais e as possíveis ações legais que seriam intentadas, tornam essa recusa altamente implausível. $\mathrm{O}$ acesso a uma consulta de cuidados de saúde primários implica o pagamento de uma taxa moderadora com o valor de $5 €$ por parte dos utilizadores, sendo que alguns grupos de pessoas, que constituem uma parte significativa da população, estão isentos (por exemplo, em 2011, aproximadamente $43 \%$ dos portugueses estavam isentos dos pagamentos de taxas moderadoras). Estes argumentos apontam no sentido de não haver barreiras financeiras ao acesso aos cuidados de saúde primários. No entanto, como já referimos, existe em Portugal um problema de insuficiência de médicos de família, que implica que a uma parte da população não é atribuído 
nenhum, criando-lhe dificuldades em garantir uma consulta numa unidade de cuidados de saúde primários, o que mais do que compensa, na nossa perspetiva, os benefícios dos baixos copagamentos.

Os médicos de família das UCSP têm um salário fixo como única fonte de rendimento, pelo que não têm qualquer incentivo a discriminar doentes, apesar de também não serem encorajados a não o fazer. Nas USF-B, por outro lado, há uma componente de capitação que é ajustada apenas pela idade, o que torna alguns doentes mais lucrativos do que outros (por exemplo, os doentes crónicos implicam custos de tratamento muito altos). Desta forma, os médicos de família podem oferecer a alguns doentes melhor tratamento do que a outros, ainda que não possam recusar tratamento a nenhum doente da sua lista. Para além disso, a componente de $\mathrm{P} 4 \mathrm{P}$ que existe no modelo de pagamento das USF cria um incentivo para que se privilegiem os doentes que mais podem contribuir para o cumprimento das metas definidas. Finalmente, não existe qualquer tipo de recompensa para o tratamento de doentes vulneráveis, ou para a redução de desigualdades na prestação de cuidados de saúde. Desta forma, consideramos que o modelo de pagamento das USF (A e B) é desfavorável à não-discriminação.

Quanto à eficiência, os médicos das UCSP não têm um incentivo específico para a procurarem, já que o pagamento que recebem é independente das despesas em que incorrem no exercício da sua atividade. Em contraste, o pagamento por capitação, bem como os indicadores nacionais relativos às despesas em medicamentos e exames, encoraja os médicos das USF a procurarem práticas clínicas tão eficientes quanto possível.

\section{Cuidados de saúde secundários}

O modelo de pagamento que se aplica aos hospitais EPE é essencialmente baseado no nível da atividade que desenvolvem, com limites de volume. É constituído por cinco componentes: (i) um pagamento por caso para doenças específicas, com limite de volume; (ii) um pagamento por episódio de internamento e consulta, com limite de volume; (iii) um pagamento per diem para internamentos de doentes crónicos; (iv) um mecanismo de pay-for-performance. Com base no contrato-programa estabelecido entre a Administração Central do Sistema de Saúde e os hospitais [33], detalhamos agora cada uma destas componentes.

\section{Componentes de financiamento}

Pagamento por caso para doenças específicas, com

limite de volume

Este mecanismo inovador tem sido implementado nos últimos anos para o financiamento de doenças específicas como o VIH/SIDA e alguns tipos de cancro. Pelo tratamento anual de doentes com estas doenças, os hospitais recebem um pagamento prospetivo fixo, independente dos cuidados prestados e de quem os presta. É importante mencionar que este mecanismo de pagamento não se aplica ao tratamento de perturbações mentais.

Pagamento por episódio de internamento, com limite de volume

O valor pago por cada internamento depende do índice histórico de casemix (baseado no GDH) dos hospitais, que, partindo de um valor base, é adaptado de acordo com as caraterísticas dos hospitais (para mais detalhes sobre a forma de cálculo deste índice, consultar [34]). Por exemplo, os internamentos no Centro Hospitalar de Lisboa Norte, um hospital universitário com um dos mais altos índices de casemix do país em 2015, são valorizados em $2.056 €$, se forem médicos, e $2.120 €$, se forem cirúrgicos. Em comparação, o Hospital Distrital de Santarém, um pequeno hospital de uma pequena cidade, que tem um índice de casemix mais baixo, recebe $1.710 €$ por internamento, quer seja médico ou cirúrgico.

Pagamento per diem para internamentos de doentes crónicos

Um valor diário é atribuído aos internamentos de doentes com doenças crónicas específicas, incluindo a psiquiatria crónica e reabilitação psicossocial. O pagamento diário para perturbações psiquiátricas é de $37,33 €$. Os hospitais EPE especializam-se no tratamento das fases agudas de doenças, mas o tratamento dos doentes crónicos exige a prestação de cuidados não agudos de longa duração. Em Portugal, estes cuidados são maioritariamente prestados por instituições sociais independentes do SNS, nomeadamente associações e ordens religiosas. Caso os hospitais optem por referenciar os doentes crónicos para estas instituições, são obrigados a pagar as suas estadias, sendo, no entanto, reembolsados em $38,89 €$ por dia de internamento. A Tabela 4 contém este e outros valores relativos ao tratamento de perturbações mentais por parte dos hospitais EPE.

Pagamento por episódio de consulta, com limite de volume

Para cada hospital, um certo volume de consultas, hospital de dia e visitas de emergência é contratualizado 
Table 4. Valores atribuídos ao tratamento de perturbações mentais nos hospitais EPE

\begin{tabular}{lc}
\hline Mecanismo de pagamento & Valor, $€$ \\
\hline Pagamento por período & Não aplicável \\
Pagamento por episódio & Variável (ICM) \\
$\quad$ Internamentos & \\
Pagamento per diem & 73,33 \\
$\quad$ Internamentos de reabilitação psicossocial & 73,33 \\
$\quad$ Internamentos de psiquiatria crónica & 38,89 \\
Internamentos de psiquiatria crónica - instituições sociais & \\
Pagamento por episódio & 99,32 \\
$\quad$ Primeiras consultas & 99,32 \\
$\quad$ Consultas seguintes & 112,53 \\
$\quad$ Primeiras consultas - comunidade/telemedicina & 109,25 \\
Consultas seguintes - comunidade/telemedicina & 30,49 \\
Casos de dia & 107,59 \\
Visitas de emergência & \\
\hline
\end{tabular}

anualmente, numa base prospetiva. $\mathrm{O}$ preço de cada um destes itens é também fixado prospetivamente e varia normalmente de acordo com o tipo de hospital. A título de exemplo, podemos referir os preços fixados em 2015. O preço das consultas variava entre $37,20 €$ e 106,85€, dependendo do tipo de hospital. Já uma visita de emergência num departamento de emergência polivalente estava avaliada em 107,59€. Finalmente, nos hospitais psiquiátricos e nos departamentos de psiquiatria de hospitais gerais, as primeiras consultas tinham o valor de $102,30 €$ e as restantes de 99,32€. O valor pago por consulta é usado para financiar todos os recursos com ela relacionados, nomeadamente análises, exames e medicação entregue exclusivamente pelos hospitais. É por esta razão que optamos por classificar o pagamento de consultas como um mecanismo de pagamento por episódio e não como FFS. Para encorajar a realização de consultas psiquiátricas na comunidade por parte de profissionais do hospital, um mecanismo de pagamento por episódio sem limite de volume foi também instituído em 2013. As primeiras consultas psiquiátricas na comunidade, bem como aquelas que recorrem à telemedicina são valorizadas em 112,53€, enquanto que o valor atribuído às restantes é de 109,25€. Contudo, relatos informais apontam no sentido de este tipo de consultas ter sido, até agora, ignorado na elaboração de orçamentos de hospitais, o que significa que, na prática, esta componente do modelo de pagamento aos hospitais ainda não foi implementada.

\section{Pay-for-performance}

$\mathrm{Na}$ base deste mecanismo, uma lista de 16 indicadores é definida nacionalmente, estando estes relacionados com acesso, qualidade dos cuidados e sustentabilidade/eficiên- cia. Para além disso, são também definidos indicadores a nível regional, pelas Administrações Regionais de Saúde. O cumprimento ou não das metas definidas por estes indicadores determina $5 \%$ do orçamento dos hospitais (como definido nos números anteriores). De notar que nenhum destes indicadores está diretamente ligado à saúde mental.

\section{Incentivos esperados}

Os incentivos que se espera que as modalidades de pagamento aos hospitais criem estão resumidos na Tabela 5. Os critérios que guiam esta análise são os mesmos de que nos socorremos no estudo dos cuidados de saúde primários, com a exceção da abrangência/envolvimento no tratamento de perturbações mentais, que não faz sentido analisar no contexto de cuidados especializados em saúde mental.

Pagamento por episódio de internamento, com limite de volume

A continuidade e a coordenação não são favorecidas por este mecanismo, que financia os internamentos sem levar em linha de conta os cuidados prestados antes e depois de eles ocorrerem, quer esses cuidados sejam prestados pelo hospital onde decorre o internamento ou por outro prestador. Como o foco deste mecanismo está apenas nos internamentos, que não têm qualquer relação com a prevenção, podemos dizer que o mecanismo é neutro no que diz respeito a este critério.

O impacto do pagamento por episódio na acessibilidade depende crucialmente da distribuição do lucro gerado pelos doentes. Se uma grande parte dos doentes necessitar de um tratamento cujo custo é superior ao valor recebido pelos hospitais para o efetuar, é expetável que existam 
Table 5. Incentivos esperados do mecanismo de pagamento aos hospitais

\begin{tabular}{lllllllll}
\hline \multirow{2}{*}{ Critério } & \multicolumn{1}{l}{ EPE } & & & & & ULS & SPA \\
\cline { 2 - 6 } & PPP & PPE & PDP & PPC & P4P & CAP & OG \\
\hline Continuidade & NA & -- & + & -- & 0 & + & 0 \\
Coordenação & NA & - & - & - & 0 & + & 0 \\
Prevenção & NA & 0 & 0 & - & 0 & + & + \\
Acessibilidade & NA & $?$ & $?$ & $?$ & 0 & + & - \\
Não-discriminação & NA & - & - & - & - & - & - \\
Eficiência & NA & + & - & + & + & + & + \\
\hline
\end{tabular}

++, altamente provável; +, moderadamente provável; 0, neutro; -, moderadamente improvável; --, altamente improvável; ?, ambíguo; NA, não aplicável; PPP, pagamento por período; PPC, pagamento por caso; PPD, pagamento per diem; PPE, pagamento por episódio; P4P, pay-forperformance; CAP, capitação; OG, orçamento global.

barreiras que dificultem o acesso dos doentes ao tratamento. Caso contrário, os hospitais preferem tratar um grande número de doentes e o acesso deverá ser facilitado. No que diz respeito à não-discriminação, é importante não nos ficarmos por uma análise superficial. Uma primeira observação poderia levar-nos a afirmar que não deve haver incentivos para negligenciar os casos mais complexos, que implicam normalmente uma maior compensação para os hospitais. Contudo, é importante ter em atenção a forma como os índices de casemix influenciam os pagamentos a receber. Em particular, devemos lembrar-nos que são definidos valores fixos para grupos de doentes que podem ter caraterísticas substancialmente diferentes, o que pode levar a que o custo de tratamento exceda o valor a receber pelos hospitais em alguns deles, mas não noutros. Caso isto seja uma realidade, os hospitais têm um incentivo para selecionar ou oferecer melhor tratamento, em termos relativos, a algumas subcategorias de doentes. Podemos também afirmar que esta forma de pagamento cria incentivos para um grande número de internamentos, através, por exemplo, da divisão de um episódio em vários, ou do favorecimento de readmissões, o que pode ser ineficiente. Este problema é amplificado pela inadequação dos GDH na área da saúde mental, apontada na literatura, que provoca um sub-financiamento para estes casos. No entanto, a existência de limites de volume mitiga este problema e o facto de serem os próprios hospitais a pagar os custos dos seus internamentos deve levá-los a procurar ser tão eficientes quanto possível. Existindo um argumento atenuado contra a eficiência e outro a seu favor, concluímos que este mecanismo de pagamento é favorável a que ela se verifique.
Pagamento per diem para internamentos de doentes crónicos

O tratamento de doentes crónicos é financiado através de um mecanismo de per diem, o que favorece internamentos muito longos. A continuidade dos cuidados de saúde deve beneficiar deste facto, na medida em que é previsível que os doentes sejam observados durante muito tempo por profissionais de saúde do mesmo hospital. Este esquema incentiva um tratamento realizado integralmente num hospital, o que prejudica a colaboração entre prestadores. Como já referimos, não faz sentido que a prevenção ocorra num contexto de internamentos, pelo que não é incentivada ou desfavorecida por este mecanismo. Assim como acontece no pagamento por episódio, o impacto deste mecanismo na acessibilidade dos cuidados de saúde depende da rentabilidade do tratamento dos doentes. Se assumirmos que os hospitais são capazes de identificar os subgrupos de doentes mais rentáveis, podemos afirmar que existe um incentivo para oferecer a alguns doentes um tratamento melhor, em termos relativos, do que a outros. Também como referido na análise do mecanismo anterior, os custos dos internamentos são suportados pelos hospitais, o que significa que estes são incentivados a prestar cada serviço médico ao menor custo possível. No entanto, a duração exagerada dos internamentos implica uma utilização ineficiente dos recursos disponíveis, porque aqueles destinados a doentes que já não necessitam de tratamento seriam mais bem aproveitados se fossem direcionados para os doentes que realmente necessitam deles. Como este mecanismo não inclui um limite de volume, consideramos que o segundo efeito domina o primeiro, e que a eficiência não é incentivada.

Pagamento por caso para doenças específicas com limite de volume

O pagamento por caso contabiliza cada serviço médico específico isoladamente, o que não favorece a continuidade nas relações entre os hospitais e os doentes. Aplica-se apenas ao tratamento que é efetuado nos hospitais, pelo que não incentiva a coordenação entre diferentes prestadores de cuidados de saúde. No entanto, as consultas psiquiátricas realizadas na comunidade são (pelo menos em teoria) mais bem remuneradas do que as que têm lugar nos hospitais, o que conduz a um tratamento eficaz, conforme referido pela OMS, quando menciona os méritos da desinstitucionalização, e também ao trabalho conjunto entre hospitais e outras instituições que os auxiliam na prestação de cuidados de saúde. É por isto que, na Tabela 5 , definimos que a coordenação é ligeiramente favorecida por este mecanismo. Não está contemplada qualquer re- 
compensa para a realização de atividades de prevenção, que consomem muito tempo e, pelo contrário, as atividades de curta duração são incentivadas, no sentido de maximizar o número de atividades realizadas e a realização de atividades rápidas é favorecida, para que o seu número seja maximizado, pelo que consideramos que esta modalidade é desfavorável à prevenção. Quanto à acessibilidade, podemos aplicar a mesma lógica que utilizámos na análise das duas modalidades anteriores, daí o sinal de ambiguidade na Tabela 5. A não-discriminação pode estar em causa com este mecanismo, já que o valor pago por consulta é fixo e o seu custo é suportado pelos hospitais, o que pode levá-los a oferecer o mesmo tratamento a doentes com necessidades diferentes. O impacto deste mecanismo na eficiência está relacionado quer com custos, quer com o nível de atividade. Por um lado, cria um incentivo para oferecer cada serviço ao menor custo possível, já que o valor pago por cada serviço é fixo e independente do seu custo, o que significa que qualquer poupança é apropriada pelos hospitais. Por outro, existe um incentivo claro para um alto nível de atividade (seja ela consubstanciada em consultas, estadias ou casos de dia, por exemplo), desde que o limite acordado não seja ultrapassado. Se o limite for superado, este incentivo é atenuado, já que não é seguro que a atividade adicional implique uma compensação financeira. Contudo, a longo prazo, pode ser uma boa estratégia para os hospitais produzirem acima do contratado, já que desta forma ganham margem para conseguir um teto de atividade mais elevado (e, portanto, um maior orçamento) em futuras negociações. Em resumo, é nossa opinião que este mecanismo conduz a um alto nível de atividade, até um certo limite. Se a atividade for exagerada e forem oferecidos mais cuidados de saúde do que seria desejável, gera-se um desperdício de recursos, que afeta negativamente a eficiência. No entanto, este efeito está limitado por um teto de atividade, enquanto que o primeiro, que vai em sentido contrário, não apresenta qualquer restrição. Desta forma, pensamos neste mecanismo como incentivador de eficiência.

\section{Pay-for-performance}

A continuidade de cuidados de saúde, colaboração entre entidades, prevenção de problemas de saúde e acesso a serviços médicos não estão relacionados com os indicadores presentes na lista que se aplica aos hospitais EPE, pelo que este mecanismo é neutro no que diz respeito a estes critérios.

A não-discriminação é posta em causa pelo risco de os hospitais oferecerem cuidados de saúde de baixa qualidade aos doentes cujo tratamento não contribui para o cum- primento dos objetivos definidos pelos indicadores (por exemplo, dando altas precoces ou evitando a readmissão de doentes). Em contraste, este mecanismo é favorável à eficiência, já que existem indicadores com ela relacionados, nomeadamente a percentagem de readmissões e estadias longas, o consumo de medicamentos genéricos e a percentagem de cirurgias de dia.

\section{Cuidados de saúde terciários}

No que diz respeito à reabilitação e prestação de cuidados de longa duração a doentes complexos ou altamente dependentes, os hospitais de agudos recebem $37 €$ diários pelo tratamento de doentes psiquiátricos crónicos. Caso um doente seja transferido para uma instalação de uma organização não-governamental, esta recebe um per diem de $38 €$ do hospital que o referenciou. Estas instituições tratam também doentes com seguros de saúde privados ou sem seguro de saúde. Apesar de não haver informações oficiais sobre a forma como as estadias destes doentes são cobradas, relatos informais apontam no sentido de consistirem também num per diem, cujo valor é geralmente superior aos $38 €$ recebidos por pacientes provenientes do SNS.

As instalações residenciais são também oficialmente financiadas através de um per diem. Os valores variam entre $12,83 €$ e 50,89€, de acordo com o grau de apoio, sendo que o limite inferior é atribuído a residências totalmente autónomas e o superior àquelas que têm uma maior necessidade de apoio [35]. As unidades sócio-ocupacionais recebem também um per diem, de 27,36€.

Os incentivos criados por um mecanismo de per diem já foram discutidos, quando nos referimos ao pagamento aos Hospitais EPE, mas voltamos a mencioná-los, agora neste contexto. Existe uma tendência para favorecer estadias longas e em grande número, enquanto que a eficiência não é promovida, a não ser que o valor do per diem seja reduzido. A acessibilidade pode ser um problema ou não, dependendo da distribuição da rentabilidade dos doentes. Existe um incentivo para discriminar pacientes, prejudicando aqueles cujo tratamento é mais caro. A desinstitucionalização e a colaboração entre instituições é favorecida nas situações em que os hospitais de agudos são responsáveis pelo pagamento das estadias dos seus doentes em instalações de organizações não-governamentais. No entanto, este caso é tão específico, que não é suficiente para nos levar a atribuir uma nota positiva a este critério. A prevenção não faz sentido neste contexto e a continuidade é privilegiada pela natureza de longo prazo deste tipo de cuidados de saúde. 


\section{Conclusão}

O pagamento a prestadores de cuidados de saúde mental em Portugal é bastante diversificado e oferece incentivos interessantes que contribuem para o cumprimento de objetivos de saúde pública. O pagamento às USF, na sua vertente de cuidados de saúde primários, é muito promissor, principalmente por combinar componentes de capitação e pay-for-performance, o que permite não apenas que sejam oferecidos cuidados de saúde ajustados às necessidades da população, mas também que o sejam de forma tendencialmente eficiente. O pagamento preço-volume aos Hospitais EPE tem também aspetos interessantes, embora seja menos ambicioso.

No entanto, parece claro que existem diferentes modalidades de pagamento para o mesmo nível de cuidados e que as modalidades para os diferentes níveis foram desenhados de forma isolada, sem articulação entre si. Esta realidade leva-nos a apontar três grandes problemas do modelo de pagamento atualmente existente:

- Diferentes modalidades de pagamento induzem práticas diferentes no mesmo nível de cuidados de saúde, o que leva a que doentes com problemas semelhantes sejam alvo de tratamentos diferentes, se não forem tratados pelo mesmo prestador. Por exemplo, nos cuidados de saúde primários, é muito provável que um doente não seja tratado da mesma forma numa UCSP e numa USF.

- O sistema não foi desenhado de forma a que os incentivos que cria nos diferentes níveis de cuidados sejam compatíveis entre si, o que pode resultar em problemas de coordenação. Por exemplo, as unidades de cuidados de saúde primários são incentivadas a referenciar para cuidados especializados em grande quantidade, mas estes nem sempre têm interesse em tratar um grande número de doentes.

- Os cuidados de saúde primários não têm incentivos nem condições materiais para tratar doentes com perturbações mentais ou para trabalhar na prevenção destes problemas. Este é um problema importante, que implica que os cuidados de saúde secundários tenham um peso que poderia ser evitado, o que, em última análise, significa que os doentes saem prejudicados.

O modelo de pagamento atual apresenta ainda outros problemas, que se manifestam em todos os níveis de cuidados de saúde:

- Os cuidados de saúde primários não são incentivados a privilegiar a continuidade de cuidados, o baixo nível de referenciação e a prevenção, com a exceção talvez das USF-B, que são pagas (também, mas não só) por capi- tação. Para além disso, as modalidades de pagamento que se lhes aplica não favorece o tratamento dos doentes mais vulneráveis, e o reduzido número de médicos de família limita o acesso aos cuidados de saúde primários, sendo que os principais prejudicados por esta realidade são os cidadãos que não têm capacidade financeira para aceder aos cuidados de saúde privados.

- O pagamento aos hospitais está basicamente dependente do nível de produção dos diferentes serviços que prestam, o que não ajuda a que exista uma visão integrada do estado de saúde dos doentes e uma concentração de esforços na prevenção, continuidade de cuidados e colaboração entre prestadores. Em particular, não é fomentada a prestação de cuidados de saúde comunitários, ou seja, fora dos hospitais.

A revisão do modelo de pagamento atual e apresentação de propostas alternativas não faz parte do âmbito deste relatório. Ainda assim, depois de concluirmos a nossa avaliação do modelo, parece-nos que a criação de modelos de pagamento inovadores, que incentivem a coordenação e integração de cuidados de saúde, em detrimento de outros simplesmente baseados em níveis de produção, é um caminho promissor. $\mathrm{O}$ atual modelo de pagamento das USF-B é um exemplo a seguir, e pode ser estendido a todas as unidades de cuidados de saúde primários, pelo menos por razões de equidade. $\mathrm{O}$ envolvimento destes cuidados no tratamento de perturbações mentais leves deve ser explicitamente incentivado e facilitado, através, por exemplo, de um mecanismo de pay-for-performance e do reforço dos recursos humanos dos cuidados de saúde primários.

\section{Apoio}

Este projeto, com o código 00065SM1, teve o apoio do Programa de Iniciativas de Saúde Pública (PT06), financiado pelo Mecanismo Financeiro EEA Grants 2009-2014.

\section{References}

1 Portugal, Ministério da Saúde, Coordenação Nacional para a Saúde Mental: Plano Nacional de Saúde Mental 2007-2016. Lisboa, Ministério da Saúde, 2008.

2 Caldas-de-Almeida J, Xavier M: Estudo epidemiológico de saúde mental. Lisboa, Faculdade de Ciências Médicas, Universidade Nova de Lisboa, 2013.

3 Observatório Português do Sistema de Saúde: Relatório de Primavera 2017. Lisboa, OPSS, 2017.

4 Portugal, Ministério da Saúde, Direção Geral da Saúde: Portugal: saúde mental em números - 2014. Lisboa, Direção Geral da Saúde, 2014.
16

Port J Public Health DOI: $10.1159 / 000486052$
Perelman et al. 
5 OECD: OECD Health Statistics 2014. Paris, OECD Publishing, 2014

6 Charlesworth A, Davies A, Dixon J: Reforming Payment for Health Care in Europe to Achieve Better Value. London, Nuffield Trust, 2012.

7 McGuire TG: Physician agency; in Culyer AJ, Newhouse JP (eds): Handbook of Health Economics, vol 1A. North Holland, Elsevier, 2000, pp 461-536.

8 Rosko MD, Broyles RW: The Economics of Health Care: A Reference Handbook. Westport, Greenwood Publishing Group, 1988.

9 The REFINEMENT (REsearch on FINancing systems' Effect on the quality of MENTal health care) Project: The REFINEMENT Decision Support Toolkit for Improving the Financing of Mental Health Care: REFINEMENT Work Package 9: Building Optimal Models of Mental Health Care Financing. Verona, The REFINEMENT Consortium, University of Verona, 2015. Available from: http://www.refinementproject.eu/.

10 Rice T: The physician as the patient agent; in Jones AM (ed): The Elgar Companion to Health Economics. Northampton, Edward Elgar Publishing, 2006, pp 261-268.

11 Robinson JC: Theory and practice in the design of physician payment incentives. Milbank Q 2001;79:149-177.

12 Barros PP: Economia da saúde, conceitos e comportamentos, ed 3. Coimbra, Almedina, 2013.

13 Ettner SL, Schoenbaum M: The role of economic incentives in improving the quality of mental health care; in Jones AM (ed): The Elgar Companion to Health Economics. Northampton, Edward Elgar Publishing, 2006, pp 286-295.

14 Dwyer DS, Mitchell OS, Cole R, Reed SK: Evaluating Mental Health Capitation Treatment: Lessons from Panel Data. Cambridge, National Bureau of Economic Research, 1995.

15 Bloom JR, Hu TW, Wallace N, Cuffel B, Hausman JW, Sheu ML, et al: Mental health costs and access under alternative capitation systems in Colorado. Health Serv Res 2002; $37: 315-340$
16 Chou AF, Wallace N, Bloom JR, Hu TW: Variation in outpatient mental health service utilization under capitation. J Ment Health Policy Econ 2005;8:3-14.

17 Knapp M, McDaid D, Amaddeo F, Constantopoulos A, Oliveira MD, Salvador-Carulla $\mathrm{L}$, et al: Financing mental health care in Europe. J Ment Health 2007;16:167-180.

18 Drozd EM, Cromwell J, Gage B, Maier J, Greenwald LM, Goldman HH: Patient casemix classification for medicare psychiatric prospective payment. Am J Psychiatry 2006; 163:724-732.

19 Zechmeister I, Osterle A, Denk P, Katschnig $\mathrm{H}$ : Incentives in financing mental health care in Austria. J Ment Health Policy Econ 2002;5: 121-130.

20 Hagenbichler E: The Austrian DRG System. Vienna, Federal Ministry of Health, 2010.

21 Jacobs R, Chalkley M, Aragón MJ, Böhnke JR, Clark M, Moran V, et al: Funding of mental health services: do available data support episodic payment? York, Center for Health Economics, 2016.

22 NHS England: Mental Health Clustering Booklet. London, NHS England Publications, 2016.

23 World Health Organization: Quality of Care: A Process for Making Strategic Choices in Health Systems. Geneva, World Health Organization, 2006.

24 Wilson A, Windak A, Oleszczyk M, Wilm S, Hasvold T, Kringos D: The delivery of primary care services; in Kringos DS, Boerma WG, Hutchinson A, Saltman RB (eds): Building Primary Care in a Changing Europe. 1. UK, European Observatory on Health Systems and Policies, 2015, pp 67-102.

25 Adair CE, McDougall GM, Mitton CR, Joyce AS, Wild TC, Gordon A, et al: Continuity of care and health outcomes among persons with severe mental illness. Psychiatr Serv 2014;56:1061-1069.
26 Caldas-de-Almeida J, Killaspy H: Long-Term Mental Health Care for People with Severe Mental Disorders. Brussels, European Union, 2011.

27 OECD: Making Mental Health Count: The Social and Economic Costs of Neglecting Mental Health Care (OECD Health Policy Studies). Paris, OECD Publishing, 2014.

28 Knapp M, McDaid D, Parsonage M: Mental Health Promotion and Mental Illness Prevention: The Economic Case. London, Department of Health, 2011.

29 Joint Action on Mental Health and Well-Being: Towards Community-Based and Socially Inclusive Mental Health Care: Situation Analysis and Recommendations for Action. Lisboa, Joint Action on Mental Health and WellBeing, NOVA Medical School, Universidade NOVA de Lisboa, 2015.

30 Portugal, Ministério da Saúde, ACSS: Metodologia de contratualização para os cuidados de saúde primários no ano de 2015. Lisboa, Administração Central do Sistema de Sáude, 2014.

31 Marcelino G, Cerveira JM, Carvalho I, Costa JA, Lopes M, Calado NE, et al: Burnout levels among Portuguese family doctors: a nationwide survey. BMJ Open 2012;2:e001050.

32 Granja M, Ponte C, Cavadas LF: What keeps family physicians busy in Portugal? A multicentre observational study of work other than direct patient contacts. BMJ Open 2014;4: e005026.

33 Portugal, Ministério da Saúde, ACSS: Contrato-programa 2015: Metodologia para definição de preços e fixação de objetivos. Lisboa, Administração Central do Sistema de Sáude, 2014.

34 Portugal, Ministério da Saúde, ACSS: Cálculo dos doentes equivalentes e do Índice de CaseMix de acordo com a Portaria n. ${ }^{\circ} 839-A / 2009$. Lisboa, Administração Central do Sistema de Sáude, 2015. Available from: http://www.acss. min-saude.pt/Portals/0/C\%C3\%A 1lculo $\% 20$ do\%20doente\%20equivalente $\% 20 \mathrm{e} \% 20$ ICM_2009_Finaln.pdf.

35 Portaria n. ${ }^{\circ} 183 / 2011$. Diário da República. $1^{\mathrm{a}}$ Série. n. ${ }^{\circ} 87$ (2011-05-05): 2540-42. 2011. 